\title{
INFORMATION TECHNOLOGY DRIVEN RESTRUCTURING OF FINANCIAL/MANAGERIAL ACCOUNTING REPORTS
}

\author{
Mysore Ramaswamy, Southern University, Baton Rouge, LA, mysore@acm.org \\ Richard Calvasina, University of West Florida, Pensacola, FL, rcalvasi@uwf.edu \\ Eugene Calvasina, Southern University, Baton Rouge, LA, ejcalvasina@cox.net \\ Gerald Calvasina, Southern Utah University, Cedar City, UT, calvasina@suu.edu
}

\begin{abstract}
The 'new' economy has given way to 'now' economy or real-time economy. This has resulted in a substantive acceleration of business measurement, assessment, reporting, and decision making processes. This information explosion has also made it harder to get the relevant and accurate information needed for good decision-making. Too often, the system designers and/or the packaged systems focus on the financial reporting output to the neglect of the internal reporting needs. Most company operational decisions are not based on the financial reporting output of the Accounting Information System (AIS). While the financial reporting is an important aspect of the AIS, financial statement information is too summarized and focuses on the company in total while most managerial decisions are centered on a subset of the business. The reports to aid in the management decision making must be focused on a particular factor so that a knowledgeable and properly informed decision made be made. In this paper, we analyze some of the factors that hinder accurate mapping of real set of relationships in the business system into the set of relationships that exist in the measurement system and propose a framework that can pave the way for better business reporting.
\end{abstract}

Keywords: Accounting Information Systems, Financial Reporting, Managerial Accounting Reporting, Real Time Economy

\section{INTRODUCTION}

The current business practices demand a much faster decision making process as many enterprises must manage their cash on a day to day basis to be able to apply it and borrow it overnight, and manage receivables and payables on a day to day basis [21]. The real time enterprise can be compared to a giant spreadsheet in which new information, such as an order, is automatically processed and percolates through a firm's computer systems and those of its suppliers. The current situation is aptly described by the following statement of former Securities and Exchange Commission (SEC) Commissioner Cynthia Glassman: "The current questions about the ability of our accounting and reporting framework to communicate meaningful information to investors arise, in part, because the economy continues to evolve at a rapid pace, while reporting standards and mechanisms are in a catch-up mode. Globalization and the emergence of new economies and capital markets have increased dramatically. Advances in technology, including the emergence of the Internet, faster and more ubiquitous and other technological developments, have changed the way companies do business, as well as changing the types of financial arrangements and instruments that businesses utilize. As the business world has become more complex, so have financial reports and accounting standards." In a typical manufacturing enterprise, the value chain model consists of the following sequence of activities: inbound logistics, operations, outbound logistics, marketing \& sales, and service. The objective is to offer the customer a level of value that exceeds the cost of activities [16, 17]. In addition to the above primary value chain activities, we also need to consider the following supporting activities: firm infrastructure, human resource management, technology development, and procurement. Supply chain management (SCM) can be defined as the combination of art and science of improving the way an enterprise finds the raw components it needs to make a product and delivers it to customers. Viewed from this perspective, SCM is an important part of the overall value chain model. This approach is useful in analyzing the impact of Information and Communications Technologies (ICT) on the manufacturing environment. 


\section{Issues in Information Systems \\ Volume 13, Issue 1, pp. 232-239, 2012}

The Financial Supply Chain is being increasingly recognized as an area offering significant potential for generating bottom-line improvements and creating competitive advantage. According to Killen Associates, a typical billiondollar company spends approximately \$27 million annually for unnecessary working capital and inefficient processing functions because they lack visibility into the Financial Supply Chain and receivables [3, 10]. It has also been estimated that the total value locked up in inefficiencies associated with the global supply chain are between $\$ 500$ billion and one trillion US\$.

Enterprise Resource Planning (ERP) systems have been developed with the twin objectives of reducing operational costs and help make better quality managerial decision making by producing reports that can be used throughout the enterprise [5, 9]. 'Work order' is the basic transaction upon which ERP implementations such as SAP have been built. As the production process progresses, the same system will link the consumption of inventory as well as track the production, shipping and accounts receivable [4]. The challenge to the management is to use the available information at the operational level for making decisions at the tactical and strategic levels. Undoubtedly, ERP systems provide vast amounts of information by utilizing their highly efficient transactional engines. The undesirable consequence is the greater degree of complexity in the decision-making process at the higher levels of management due to the increased volume of information available to managers. Because that information has been generated from a 'template' approach and does not differentiate between different types of data. Clearly, there is a need for an interface between transactional data / information and tactical decision-making. Galway and Hanks [8] categorize data into three groups: operational, conceptual, and organizational. Problems with operational data can occur due to missing data, invalid data, or inaccurate data. Conceptual data errors occur as a result of imprecise or ambiguous definition of data. Errors in organizational data occur due to disconnects between organizations that generate and/or use data. The rest of this paper is organized as follows. Features of accounting information are described in the next section. This is followed by a discussion on the design considerations for accounting information systems. The need to restructure financial/managerial reporting and how Information Technology (IT) can aid this process is discussed subsequently. A summary is presented in the last section.

\section{FEATURES OF ACCOUNTING INFORMATION}

The output of an accounting information system has to meet the user's requirements. There are some features that ensure quality. For example, IFRS - International Financial Reporting Standards, requires that the accounting information is understandable, relevant, reliable, and comparable information. Accounting information can be used by business owners to conduct a financial analysis of their companies. Accounting information has quantitative and qualitative characteristics [1,6]. Quantitative characteristics refer to the calculation of financial transactions. Qualitative characteristics include the business owner's perceived importance of financial information. Incorrect or inappropriate information can adversely affect managerial decision-making.

Accounting information must be understandable. This is an important qualitative characteristic for small business owners as many of them do not have strong accounting background. Financial information that is too technical or cannot be understood by a layperson can be ineffective for business owners. Business owners need accounting information that is applicable to the business decision at hand [24, 26]. Accounting information has to relate to a specific time period and contain information regarding individual business functions that will enable business owners to conduct a trend analysis when reviewing financial information.

The need for reforming financial reporting using the capabilities of information technology was first initiated by the Enhanced Business Reporting Consortium (EBRC) [28]. This is a consortium of stakeholders collaborating to improve the quality, integrity, and transparency of information used for decision-making in a cost effective, time efficient manner. Figure 1 illustrates the components of EBRC Model. The major components are: System Reliability, Financial Measures, Non-Financial Measures, Information Discrimination, Understandable Disclosures, and Corporate Accountability [12,14]. The problems of business reporting are succinctly described in the following statement by Rebecca McEnally, project director of the Comprehensive Business Reporting Model: "As businesses develop new products and services, the financial reporting model must keep pace ensuring that financial statements 


\section{Issues in Information Systems}

Volume 13, Issue 1, pp. 232-239, 2012

are relevant, clear, accurate, and complete. Investors worldwide are too often in the dark about the true value of companies because accounting practices fail to reflect the economics of today's business operations."

The problems in business reporting are compounded by the changes that are occurring in the way in which firms transform capital into returns. In the past, the main function of the firm was to apply unskilled labor into physical assets, which essentially meant that the reporting concentrated on the disposition of those tangible assets, adequately captured firm performance. Nowadays firms create value by the use of such intangible assets as knowledge and the skills of its workers with the result that the relationship between its physical assets and its performance is greatly reduced [28]. This will result in two types of problems: (a) A measurement issue of how to account for the presence and role of intangibles, and (b) An incentive problem in that this weaker relationship opens up a wider scope for managers to manipulate earnings.

Vasarhelyi and Alles [28] provide the following example. Cisco Systems wrote-down its inventory by $\$ 2.25$ billion, an amount larger than the inventory value in its books. One explanation is that the write-down related to the value of inventories that could not be sold by its suppliers in the value chain where Cisco had a contractual or moral obligation. In particular, during the e-commerce boom, Cisco had offered many of its dot-com customers' vendor financing in exchange for sales contracts, while signing contracts itself with downstream suppliers in anticipation of tight demand. These obligations were not reflected anywhere in the financial statements, thus, in hindsight, clearly overstating the firm's profit potential. Of course, even granting these measurement problems, there was also the suspicion that the sheer magnitude of the write-off resulted from the use of the well-known tactic of the 'big bath', in which if reporting some bad news is unavoidable, the best option is to take advantage by writing off all other possible bad news in advance in one shot, thereby creating reserves to boost income in the future.

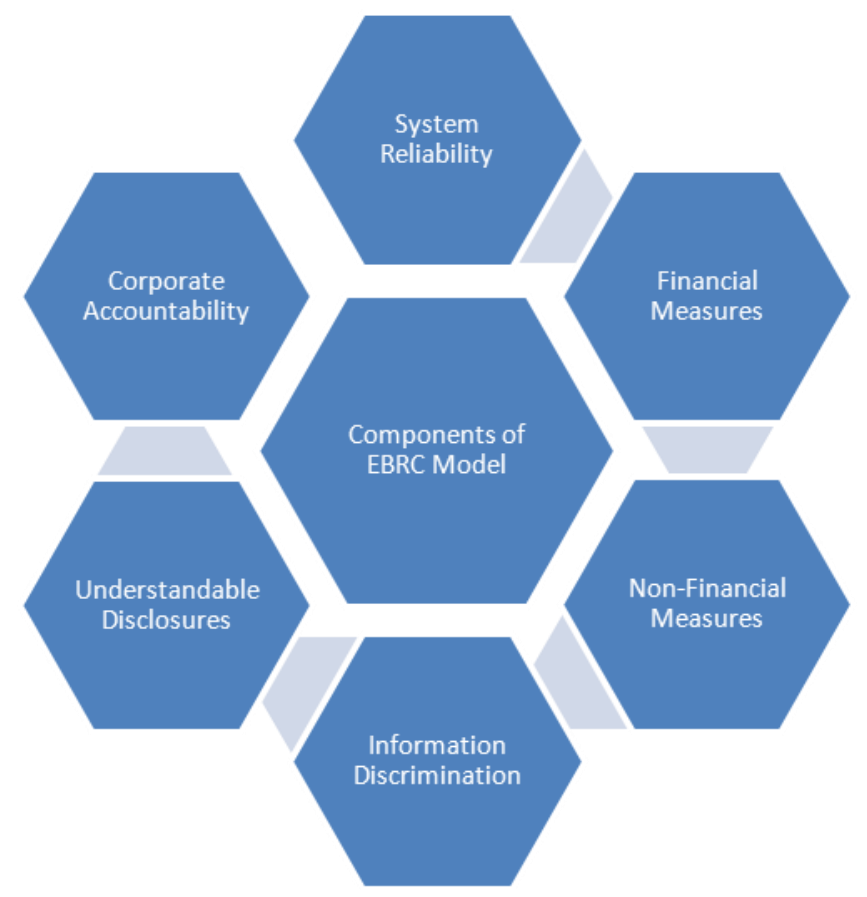

Figure 1. Components of Enhanced Business Reporting Consortium (EBRC) Model (Adapted from [28])

The above example illustrates the difficulty that users face today with financial reports. This is not an example of fraud, but rather an example of the systemic inability of the current financial reporting system to meet the needs of users to understand the ways in which complex organizations perform and to hold their managers accountable. This 


\section{Issues in Information Systems \\ Volume 13, Issue 1, pp. 232-239, 2012}

example also indicates how even long established and relatively uncontroversial rules on inventory evaluation could not guarantee that different firms will apply those rules in the same way, given the underlying ambiguity of what is being measured. Evidently, a strong case can be made for more information disclosure to enable stakeholders to better discern the purpose and meaning of each transaction.

\section{ACCOUNTING SYSTEM DESIGN CONSIDERATIONS}

During the development stage of the Accounting Information System (AIS), it is of paramount importance to determine the reporting needs that will have to be provided by the AIS. Too often, the system designers and/or the packaged systems focus on the financial reporting output (Balance Sheet, Income Statement, and Cash Flow Statement) to the neglect of the internal reporting needs. Most company operational decisions are not based on the financial reporting output of the AIS [25, 29, 30]. While the financial reporting is an important aspect of the AIS, financial statement information is too summarized and focuses on the company in total while most managerial decisions are centered around a subset of the business and the reports to aid in the management decision making must be focused on a particular factor so a knowledgeable and properly informed decision made be made.

The design of AIS must start with an analysis of the business which includes $\mathrm{ABC}$. But $\mathrm{ABC}$ is not enough. The initial analysis must also identify the organizational structure of the business (up-to-date organization chart) as well as a job description for each manager identified by the organization chart. Each manager must also be interviewed to identify what information he or she requires/needs to properly run his or her part of the business. Once this analysis is done, the output reports to support the decisions that the individual managers make can be prepared. The next stage is to design the appropriate input reports so that the data can be collected and coded in the proper manner.

The coding scheme for the collected data is one of the most important keys for the AIS to properly supply both the financial and the managerial reports. This coding scheme must have at least three parts (four if the activities identified in the $\mathrm{ABC}$ analysis do not match the organization chart). The three components include an Identification Code (ID) a General Ledger Code (GL), and a Subsidiary Ledger Code (SL). In order to assign responsibility for the different economic transactions that occur in any business, it is necessary to identify what individual/department is responsible for the economic activity that has occurred. This usually is the first part of the code. It allows for the identification of responsibility for the event and the accumulation of the data up the organization path. For example, the spending of money in a particular department can be accumulated up the particular organization path to the vice president of production level. If the departments of a business do not match the activities identified in the $\mathrm{ABC}$ analysis, than the ID code must be expanded to identify the particular activity for which the expenditure/economic event has been incurred.

The second part of the code is the General Ledger Code. This code is required for two purposes. The general ledger represents nothing more than the expansion of the basic accounting equation Assets equal Liabilities plus Owner Equity. The general ledger code ensures that debits equal credits and that the data input journal entries, are in balance and as result the general ledger stays in balance. The General Ledger is the basic source for the preparation of the financial statements. So it is a must that it says in balance. The last part of the coding scheme, the Subsidiary Code, provides for the detail that must be present in the internal reports. For top management, summary recap data as found in the Balance Sheet, Income Statement, and Income Statement is enough. But as you move down the chain of command to the lower levels of management, the reporting becomes more and more detailed [13, 20]. As a result, summary recap data is insufficient. The reporting becomes much more detailed and in many cases, unlike the financial reports, uses a unit of measure other than dollars. These lower level reports must be tailored to the needs of the individual manger and must focus on a single factor.

Because of the inherent differences in the types of decisions that managers must make as opposed to investors, the reporting is very different. Investors are looking at the business in total and trying to make comparisons evaluating one company against another as to the best place to put their investment dollars. Mangers on the other hand usually are looking at pieces and parts of the business. 


\section{Issues in Information Systems}

Volume 13, Issue 1, pp. 232-239, 2012

\section{RESTRUCTURING OF FINANCIAL/MANAGERIAL REPORTS}

If all internal and external stakeholders in the firm shared the same information about how the firm has performed in the past and had similar expectations as how it will perform in the future, financial reporting would not be all that critical. Such an ideal situation does not exist, and those within the firm are inevitably in a better position to know its state than those stakeholders outside of it [27]. The internal stakeholders have a significant information advantage if the internal reporting system has been set up properly. Herein lays the fundamental informational asymmetry. Shareholders only care about the financial performance of the firm as reflected in the market price. Managers' main concern would be the optimal way to leverage the assets of the company. Other stakeholders in the company such as employees, creditors, suppliers, customers, and local agencies have their own interests and look to managerial accounting reports rather than financial statements to obtain relevant information that will help in their decision making. Figure 2 denotes the mapping of the Empirical Relationship System to the Numerical Relational System. The Empirical Relational System represents the 'real' set of relationships in the economic system such as Sales, Obligations to Collect, Obligations to Pay, and Obligations to Perform Services. Numerical (or Representational) Relational System represents the set of relationships that exist in the measurement system such as Sales Ledgers, Inventory Ledgers, Accounts Receivables, Accounts Payable, and Accruals. This type of mapping framework provides a means of examining the relationship between underlying business processes and their measurement through accounting, with the obvious implication that when one changes, so must the other. Over twenty years ago, this logic was applied by management accountants when they developed Activity Based Costing to better match cost allocation with the firm's then increasingly automated production process.

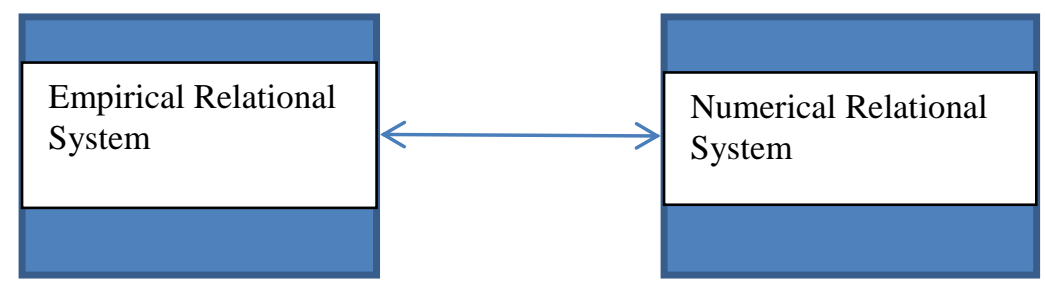

Figure 2. Mapping of Reality and its Measurement (Adapted from [27])

Empirical Relational Systems pertaining to today's businesses have vastly changed when compared to traditional organizations in the following respects: shortened business cycle, rapid feedback loop, and decision function modulating the feedback loop. Based on the analysis conducted by Vasarhelyi [28], in order to render an authentic mapping, the following questions need to be asked:

- Should accountants measure levels for the balance sheet of items that are elements in the value chain but not belonging to the entity, such as supplier managed inventories?

- Do they need to measure the levels at the partners that supply this inventory?

- Do accountants need to consolidate these values along the value chain to represent the situation of the value chain?

- Within the framework of the Numerical Representational System, are there factors to be measured that are not numerical, such as flow of information about the company, patents, ethical tone, etc.?

- Are the rules of valuation linking the two systems constant or variable depending on contingencies?

- Should the systemic risks and element specific risks be disclosed?

- Should the assumed relationships of business elements and the ensuing operational business models be disclosed?

Enterprise Resource Planning (ERP) systems are successful in achieving efficiencies in supply chain management. However, the same cannot be said regarding the mapping of business transactions into financial reports using 


\section{Issues in Information Systems}

Volume 13, Issue 1, pp. 232-239, 2012

modules such as SAP Financial Accounting modules. In order to ensure an accurate mapping of transactions, it is essential that accuracy has to be assured at the following levels: Process Level, Data Level, and Opinion Level. At the Process Level, all processes internal and outsourced need to be monitored, consolidated, and the output of this level feeds into the next level, Data Level. Here all the data is verified and the output feed to the next level, Opinion Level where reports are generated. Methods of continuous assurance have to be developed for all three of these levels in order to properly monitor the reporting of transactions in this digital age. The success of digital accounting will depend on the following factors: (a) Incorporating filters that limit direct takeover in the accounting database from in and out of the enterprise, without the prior verification by the specialized staff, and (b) The manner in which the specialized staff process the data in their database simultaneously with the data already processed by other subsystems.

To make the information produced and provided in the electronic accounting information system more reliable, electronic accounting principles were developed by the International Federation of Accountants (IFAC). These principles can be broadly classified as Security Principles and Process Principles. Figure 3 displays the preferred quality characteristics of an Accounting Information System (AIS). Based on the definition of the International Organization for Standardization, quality is a group of features and characteristics of product, process, or services that are relative to a set of requirements that will result in user satisfaction. If those inherent characteristics meet all requirements, high or excellent quality is achieved. If those characteristics do not meet all requirements, a low or poor quality is achieved. To enhance quality, it is necessary to minimize or eliminate those activities that do not add value to business entity. The quality of AIS depends on input quality, data processing quality, and output quality.

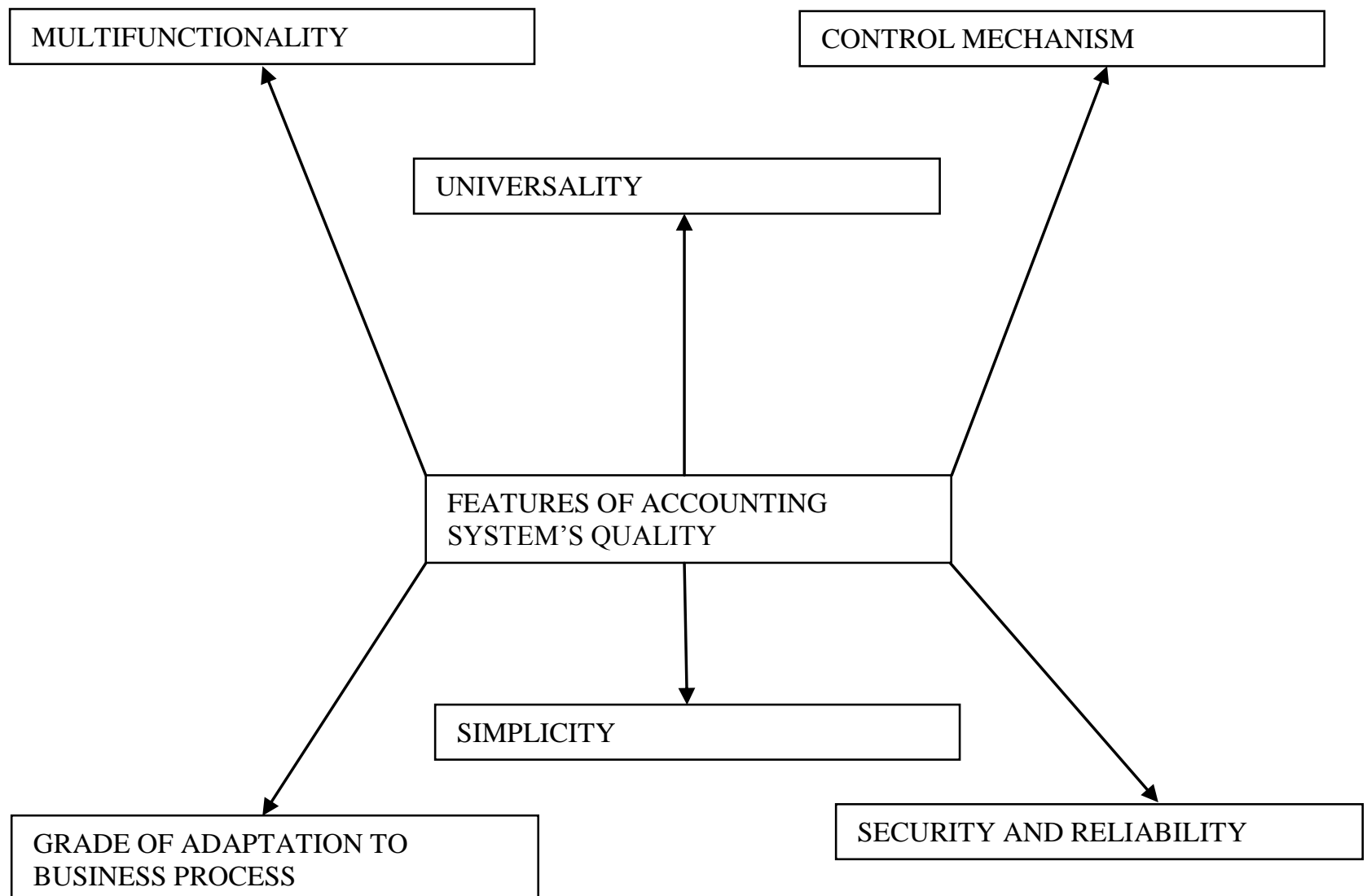

Figure 3. Features of Accounting Information System's Quality (Adapted from [24]) 


\section{Issues in Information Systems}

Volume 13, Issue 1, pp. 232-239, 2012

\section{CONCLUSION}

Accuracy of financial and managerial reports is very critical to successful business management. Accounting information systems of the past focused on the recording, summarizing, and validating of data primarily for the purpose of preparing the Balance Sheet, the Income Statement, and the Cash Flow Statement (formerly known as the Funds Flow Statement). In today's modern fast paced business environment, the internal reporting needs have become ever more critical. The proper preparation of Internal Reports for the purpose of communicating the necessary information for decision making can make or break a company. While modern day systems can collect enormous amounts of data, and process it quickly, they still suffer from the same problem of focus that the paper and pencil systems had. Internal reports are poorly done and they are not the Accounting Information System's main focus. External financial reporting is. Today's real-time economy calls for a system that can integrate various transactions that occur in geographically dispersed entities and maintain fidelity of mapping when reports are generated. Chief among the concerns when developing these systems are the determination of what information needs managers have and the proper coding of the data to ensure that the data needed for proper reporting has been collected in a manner to support the reports needed to supply managers the information needed for their decision making properly. Innovations in Information Technology (IT) have provided means to track all transactions that occur in an enterprise. By ensuring that these are tracked through the various levels in real time, the financial and managerial reports generated will meet all the quality requirements.

\section{REFERENCES}

1. Alves, M. C. G. (2010). Information Technology Roles in Accounting Tasks - A Multiple-Case Study. International Journal of Trade, Economics, and Finance, Vol. 1, No. 1, 103-107.

2. Barry, J. (2003). Lessons Learned from Physical Supply Chain. Inside Supply Management, 14, (5), 21.

3. Calvasina, R. et al. (1995). Internal Reporting - Help or Frustration? CPA Journal, November, 1995.

4. Carlton, F. et al (2005). Understanding the Impact of Enterprise Systems on Management Decision Making: An Agenda for Future Research. The Electronic Journal of Information Systems Evaluation, Vol. 8, No. 2, pp. 99-106.

5. Carton, F. et al. (2005). Understanding the Impact of Enterprise Systems on Management Decision Making: An Agenda for Future Research. The Electronic Journal of Information Systems Evaluation, 8 (2), 99-106.

6. Cooper, R. et al (1988). How Cost Accounting Distorts Product Costs. Management Accounting, 22 - 26.

7. Fontelera, J. (2007). Quest for the RFID Supply-Chain Holy Grail: ROI. Converting Magazine, 25(9), 3535.

8. Galway, L. A. and Hanks, C. H. (1996). Data Quality Problems in Army Logistics. Rand, Santa Monica, CA

9. Ge, Mouzhi, \& Helfert, M, (2007). A Review of Information Quality Research in Information System and Decision Making. Proceedings of the IADIS International Conference on e-Society, 467-470.

10. Handfield, R. and Nichols, E. (2002). Supply Chain Redesign. Upper Saddle River, NJ: Prentice Hall.

11. Hardgrave, B. C., Langford, S., Waller, M., \& Miller, R. (2008). Measuring the Impact of RFID on Out of Stocks at Wal-Mart. MIS Quarterly Executive, 7(4).

12. Hartley-Urquhart, Roland (2006). "Managing the Financial Supply Chain," Supply Chain Management Review.

13. Healy, P. M., \& Palepu, K. G. (2001). Information Asymmetry, Corporate Disclosure, and the Capital Markets: A review of the Empirical Disclosure Literature. Journal of Accounting and Economics, 31 (2001), 405-440.

14. Hirschey, M. (2000). Managerial Economics. New York, NY: The Dryden Press.

15. Hongren, C. T et al. (2000). Cost Accounting: A Managerial Emphasis. Upper Saddle River, NJ: Prentice Hall.

16. Johnson, H. Thomas. (1992). It's Time to Stop Overselling Activity Based Costing. Management Accounting, September, 26-35.

17. Kaplan, R. S., Weiss, D., et al. (1997). Transfer pricing With ABC. Management Accounting, May, 20-28. 


\section{Issues in Information Systems}

Volume 13, Issue 1, pp. 232-239, 2012

18. Lee, John Y. (1987). Managerial Accounting Changes for the 1990s. Artesia, CA: McKay Business Systems.

19. McFarlan, W. E. (1984). Information Technology Changes the Way You Compete. Harvard Business Review, 62(3), 98-103, May/June.

20. Memis, M. U. (2011). E-Accounting: An Evaluation on the Turkish Case. European Journal of Economics, Finance, and Administrative Sciences, Issue 38, 155-163.

21. Neuman, B. R. and Jaouen, P. R. (1986). Kanban, ZIPS, and Cost Accounting: A Case Study. In Focus on Industry, Journal of Accountancy, August, 132-141.

22. Ogden, Jeffrey, A. et al. (2005). Supply Management Strategies for the Future: A Delphi Study. The Journal of Supply Chain Management, 41 (3), 29-48.

23. Porter, Michael (1985). Competitive Advantage: Creating and Sustaining Superior Advantage, New York: Free Press.

24. Sacer, I. M. et al. (2006) Accounting Information System's Quality as the Ground for Quality Business Reporting. Proceedings of IADIS International Conference on e-Commerce, 59-64.

25. Sori, Z. M. (2009). Accounting Information Systems (AIS) and Knowledge Management: A Case Study. American Journal of Scientific Research, Issue 4, 36 - 44.

26. Vakilifard, H., et al. (2011). Information Asymmetry Gap Analysis between Users and Preparers of Accounting Information under Qualitative Characteristic of Financial Reporting: Evidences of Iran. International Journal of Academic Research, 3 (2), 231-241.

27. Vasarhelyi, M. A. and Alles, M. G. (2008). The "Now" and the Traditional Accounting Reporting Model: Opportunities and Challenges for AIS Research. International Journal of Accounting Information Systems, Issue 9, $227-239$.

28. Vasarhelyi, M. \& Alles, M. G. (2008). Reengineering Business Reporting Creating a Test Bed for Technology Driven Reporting. International Journal of Digital Accounting Research, 8 (14), 97-114.

29. Weygandt, J. J. et al. (2002). Management Accounting. New York, NY: John Wiley. 140-143.

30. Wilkinson, J. W. (1993). Accounting Information Systems. New York, NY: John Wiley. 